\title{
Research Paper \\ The effectiveness of interpersonal problem solving education on the social problem of young women prisoners
}

\section{Maral Haghighi Kermanshahi ${ }^{1}$, Keivan Kakabaraee ${ }^{2}$}

1. Ph.D Student, Department of Psychology, Kermanshah Branch, Islamic Azad University, Kermanshah, Iran. 2. Associate Professor, Department of Psychology, Kermanshah Branch, Islamic Azad University, Kermanshah, Iran.

Citation: Haghighi Kermanshahi M, Kakabaraee K. The effectiveness of interpersonal problem solving education on the social problem of young women prisoners. J of Psychological Science. 2021; 20(105): $1617-1629$.

URL: https://psychologicalscience.ir/article-1-981-fa.html
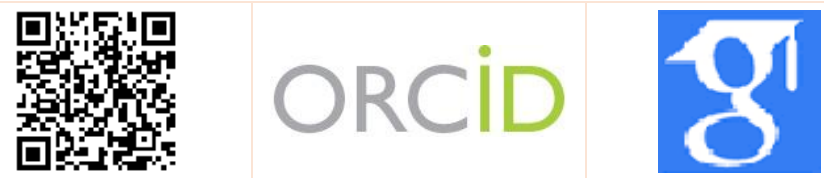

\subsection{7/JPS.20.105.1617}

\section{A R T I C L E I N F O A B S T R A C T}

Keywords:

interpersonal problem

solving,

social problem solving,

women,

prisoners

Received: 29 Sep 2020

Accepted: 24 Oct 2020

Available: 22 Nov 2021
Background: Many studies have examined the effectiveness of problem solving on social problem solving among different samples, but no study that has examined interpersonal problem solving on social problem solving of women prisoners has not been conducted in Iran.

Aims: The aim of this study was to investigate the effectiveness of interpersonal problem solving on the social problem of women prisoners.

Methods: The research design was a pretest-post test design with a control group. The statistical population of this study includes all young female offenders imprisoned in Kermanshah central prison that they were serving their sentences in 2019 . In this study 30 young women were imprisoned by the available sampling meted were selected and randomly divided into two experimental (15n) and control (15n) groups. Then 10 two-hour sessions were held every week for two interpersonal problem -solving workshops for the experimental group. After completing the post -test training problem it was implemented in both experimental and control groups. To gather information from the social problem solving questionnaires of Desorila et al (2004). Then the research data were analyzed by multivariate analysis of covariance.

Results: Results According to the participants, in two stages of pre-test-post-test showed that compared to the control group in the experimental group, between pre-test-post-test scores in all subscales of social problem solving including positive orientation, negative orientation, logical style and impulsivity style / carelessness and avoidance style was a difference.

Conclusion: Therefore, interpersonal problem-solving training can be used as a corrective and preventive intervention program to increase the social problem-solving of young women prisoners.

* Corresponding Author: Keivan Kakabaraee, Associate Professor, Department of Psychology, Kermanshah Branch, Islamic Azad University, Kermanshah, Iran.

E-mail:kakabaraee@gmail.com

Tel: (+98) 9122257860

2476-5740/ (C) 2021 The Authors. This is an open access article under the CC BY-NC-ND license

(https://creativecommons.org/licenses/by-nc/4.0/). 


\section{Extended Abstract}

\section{Introduction}

Social problem solving is a cognitive behavioral process in which a person tries to identify and discover adaptive and effective solutions for problem situations that are encountered in daily life.

Daresh et al., (2018)indicated that the most common cognitive strategies for solving problems include guessing and testing a regular list of modeling to estimate sub-problematic upside down, creating a table and logical reasoning (cited in Falaman Mahmoudnia Ghaedi \& Maghami 2020).

Incarcerated people receive less support because of interactive problems and inability to understand others (Erickson et al., 2017 cited in Feizabadi, 2019). One of the important areas in this regard is considering the psychological development of prisoners' social personality through the interpersonal problem-solving skills training (Boxan 1993, 2001; Williams, 2005).

A review of literature shows that the effect of problem solving among different groups of preschool society of students in clinical communities has been investigated, while there no study has been conducted on the effectiveness of problem solving among femaleprisoners in Iranso far.

Other reasons for this research include cultural and geographical impacts that can increase the richness of knowledge and information about female prisoners which lead to greater adaptation to the surrounding environment after their release from prison.

\section{Method}

The present study is quasi-experimental using a pretest-post-test design with a control group. In this design, the participants were randomly assigned to the experimental and control groups, and then the treatment is provided. The statistical population of this study is all young women imprisoned regardless of the type of crime in Kermanshah central prison in 2019.

According to the prison report, 98 young women are presently serving their sentences in women's central prison, 30 of whom were selected as samples and randomly assigned to two groups of 15 in experimental and 15 in control groups.

Inclusion criteria comprised of age range from 22 to 39 years and interest in participation in research.

Exclusion criteria included less than four months of lack of interest and cooperation in participating in interpersonal problem-solving workshop sessions and substance abuse.

Instruments: Social Problem Solving Questionnaire D'Zurilla, Nezu \&Maydeu-Olivares developed in 2004.This instrument has 25 Likert questions, with a minimum score of 25 and a maximum of 125 . The reliability index was. 8 based on Cronbach's alpha. After the legal process, the pre-test stage was performed for both experimental and control groups. Then, the interpersonal problem-solving training of colleagues (2007) was conducted for two hours a week in 10 sessions for the experimental group. It was later analyzed by SPSS software from both descriptive and inferential aspects.

\section{Results}

The minimum and maximum ages were 19 and 38 years, of which $63.3 \%$ of participants were married and $36.7 \%$ were single. The education rate of prisoners under diploma was $80 \%$ and over diploma was $20 \%$.

The results of Table 2 including the results of multivariate analysis of variance show the difference between the scores of the two experimental and control groups in different dimensions of social problem solving. Considering square one, it can be said that $49 \%$ of these changes were related to the effect of training and statistical power equal to one which indicates that there is no possibility of type II error.

Table 3 shows that in the positive orientation variable, the results of the inter-test effects test were significant after adjusting the pre-test effects of the noun value in the group. 
Table 1. Mean and standard deviation of social problem solving in experimental and control groups

\begin{tabular}{cccccc}
\hline Control & \multicolumn{2}{c}{ Experiment } & Stage & Variables \\
\hline Standard Deviation & Average & Standard Deviation & Average & & \\
\hline $2 / 46$ & 4.13 & $2 / 83$ & $4 / 07$ & Pre-test & \multirow{2}{*}{ Positive Orientation } \\
$2 / 35$ & $4 / 22$ & $2 / 41$ & 7.65 & Post-test & \\
$1 / 99$ & $6 / 46$ & $2 / 07$ & $6 / 94$ & Pre-test & Negative orientation \\
$1 / 84$ & $6 / 82$ & $1 / 92$ & $4 / 98$ & Post-test & \\
$2 / 61$ & $4 / 29$ & $2 / 27$ & $4 / 16$ & Pre-test & Logical style \\
2.44 & $4 / 47$ & $2 / 02$ & $6 / 21$ & Post-test & \\
$2 / 83$ & $5 / 86$ & $3 / 19$ & $5 / 98$ & Pre-test & Impulsivity / carelessness \\
$2 / 91$ & $6 / 17$ & $2 / 60$ & $3 / 11$ & Post-test & \\
$2 / 79$ & $5 / 10$ & $3 / 18$ & $5 / 69$ & Pre-test & Avoidance style \\
$1 / 77$ & $4 / 59$ & $1 / 97$ & $3 / 71$ & Post-test & \\
\hline
\end{tabular}

Table 2. Results of multivariate analysis of covariance on the mean scores in the post-test stage by controlling the effect of the pre-test Statistical power Eta squared

$\begin{array}{cccc}\mathrm{P} & \mathrm{F} & \mathrm{df} 2 & \mathrm{~d} f \mathrm{C} \\ 0 / 001 & 11 / 35 & 28 & \end{array}$

df1 Amount

$0 / 207$

Wilkes Lambda Statistical index

$10 / 493$ (1)

\begin{tabular}{|c|c|c|c|c|c|c|c|}
\hline $\begin{array}{c}\text { Statistical } \\
\text { Power }\end{array}$ & $\begin{array}{c}\text { Eta } \\
\text { Squared }\end{array}$ & $\mathrm{F}$ & $\begin{array}{c}\text { Average } \\
\text { squares }\end{array}$ & Df & $\begin{array}{c}\text { Total } \\
\text { Squares }\end{array}$ & $\begin{array}{l}\text { Source of } \\
\text { changes }\end{array}$ & Variables \\
\hline 1 & $0 / 392$ & $12 / 380$ & $72 / 229$ & 1 & $72 / 229$ & Group & Positive orientation \\
\hline 1 & $0 / 366$ & $12 / 110$ & $72 / 210$ & 1 & $72 / 210$ & Group & Negative orientation \\
\hline 1 & $0 / 435$ & $13 / 127$ & $78 / 625$ & 1 & $78 / 625$ & Group & Logical style \\
\hline 1 & $0 / 311$ & $11 / 570$ & $68 / 999$ & 1 & 68/999 & Group & Impulsivity / carelessness \\
\hline 1 & $0 / 289$ & $9 / 519$ & $61 / 244$ & 1 & $61 / 244$ & Group & Avoidance style \\
\hline
\end{tabular}

\section{Conclusion}

This study was conducted to investigate interpersonal problem solving training among young female prisoners in Kermanshah in 2019. The findings showed that interpersonal problem solving program training increases and improves positive orientation and logical problem solving style. It also reduces work and negative orientation of avoidance problem solving styles and impulsive carelessness.

The results of the present study were in line with the findings of Baduk Hunter. In other words, their findings showed that cognitive-behavioral interventions cause novel changes in the social lifestyle of prisoners who abused drugs. They became social and reacted to social issues with a more rational vision.

In explaining this issue, it should be noted that those who do not have the ability to solve logical problems when dealing with obstacles may feel defeated by impulsive behaviors, become aggressive or adopt isolation as a strategy for dealing with problematic situations (D'Zurilla, \& Nezu, 2010; Sarmento, 2015).
Also, when the training and instructions provide a path and re-open the process of defining and expressing the problem, a lot of progress will be made in the quantity and quality of solutions. This will reduce negative behaviors by adopting a positive orientation and logical style. For example, cooperation increases empathy with others (Kakabraee, 2018).

In order to explain the results, focusing on thinking enables women prisoners to adopt a positive attitude and describe the solution in the face of interpersonal and interpersonal issues. It also helps with their intellectual ability and emotional control.

\section{Ethical Considerations}

Compliance with ethical guidelines: Ethical considerations like gaining the informed consent of the participants and the confidentiality of responses were considered in this research.

Funding: This study hadn't financial support.

Authors' contribution: The first author was the senior author, the second were the supervisors.

Conflict of interest: the authors declare no conflict of interest for this study.

Acknowledgments: we would like to appreciate the participants in this research. 


\section{اثربخشى آموزش حل مسئله بينفردى بر حل مسئله اجتماعى زنان جوان زندانى

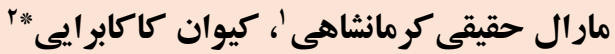

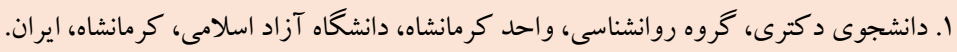

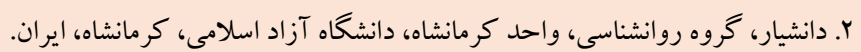

\section{جكيده}

زمينه: مطالعات زيادى به بررسى اثربخشى حل مسئله بر حل مسئله اجتماعى در بين نمونههاى مختلف برداختند، اما يُوهشى كه در آن به

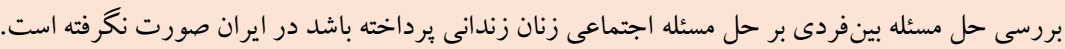

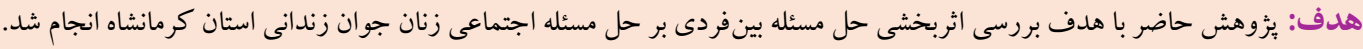

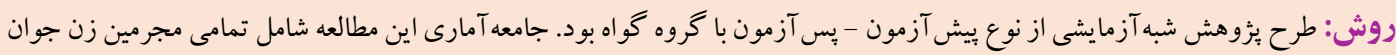

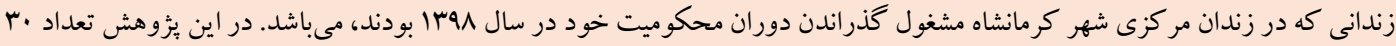

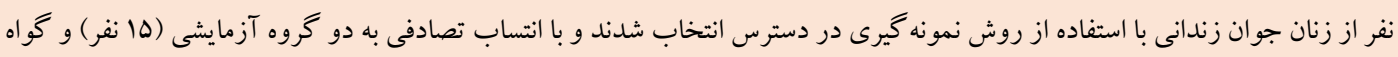

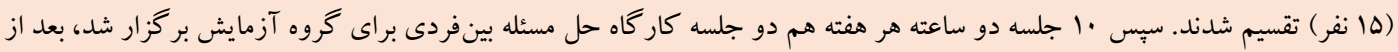

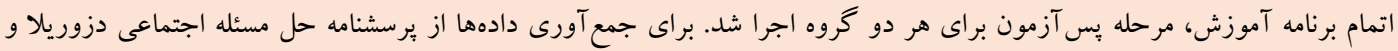

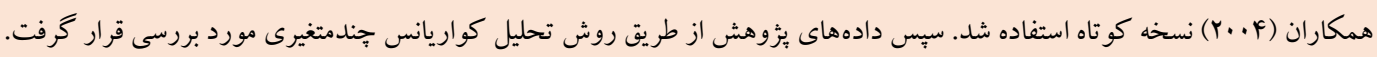

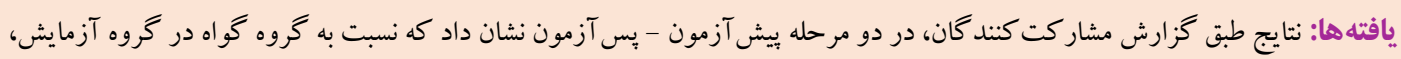

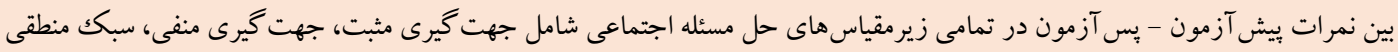

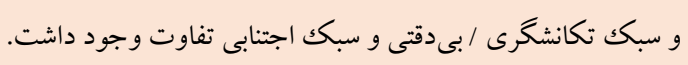

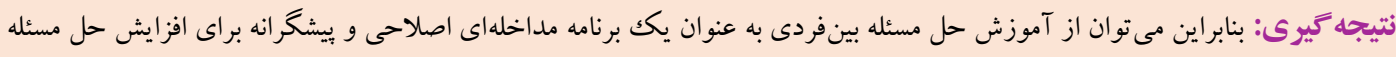

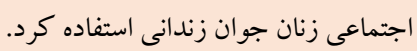

مشخصات مقاله

كليدوازهها: حل مسئله بينفردى، حل مسئل اجتماعى،

دريافت شده:

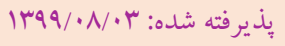

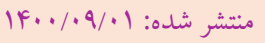

* نويسنده مسئول: كيوان كاكابرايى، دانشيار، گروه روانشناسى، واحد كرمانشاه، دانشكاه آزاد اسلامى، كرمانشاه، ايران.

رايانامه: kakabaraee@gmail.com

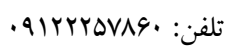


شخصيتى و اجتماعى زندانيان، از طريق آموزش مهارتهاى حل مسئله بين

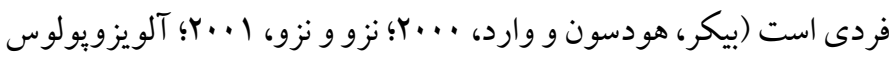

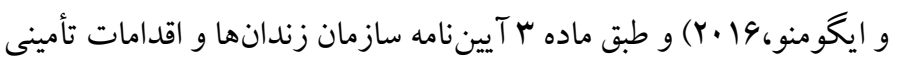

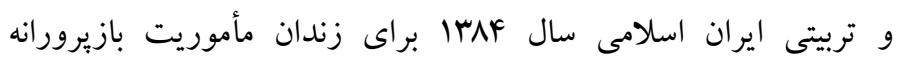

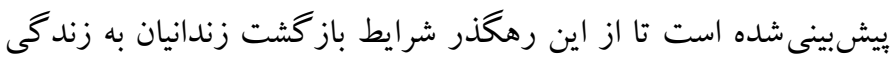

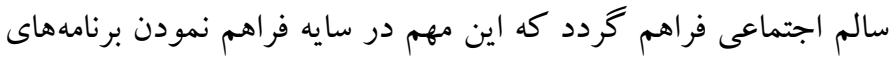

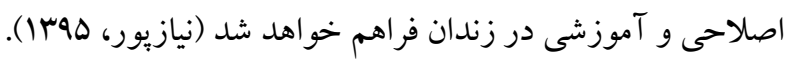

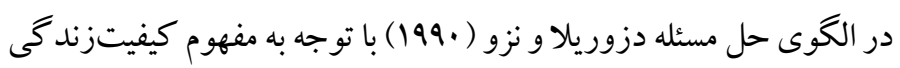
كه در آن ابعاد مختلفى نظير بهزيستى مورد توجه است و بسيارى از زندانيان

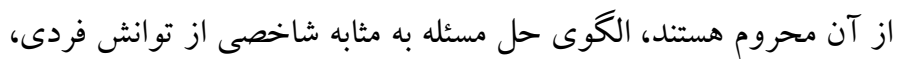

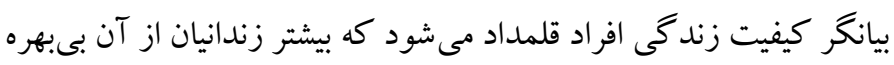
هستند. بنابراين امروزه در سراسر دنيا در بستر زندانها از طريق برنامه هاى

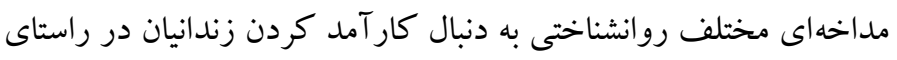
ارتقاى حل مسئله اجتماعى است و تلاشهاى فراوانى نيز صورت گرفتئه است از جمله مطالعات خدايارى فرد، يونسى، اكبرى، زردخانه، فقيهى و

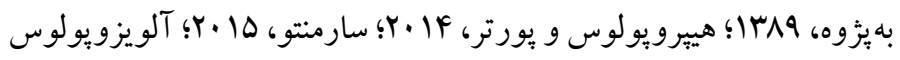

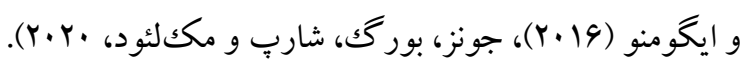
همواره مداخلات روانشناختى از جمله آموزش حل مسئله بين فردى يك ونك عنصر تعيين كننده در برنامه هاى ارتقاى كيفيت روابط اجتماعى (نزو و نزو،

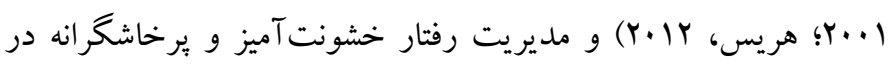
تمامى محيطهاى اجتماعى از جمله زندان بوده است (ويلى و جاروز،

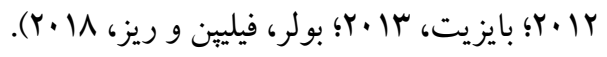

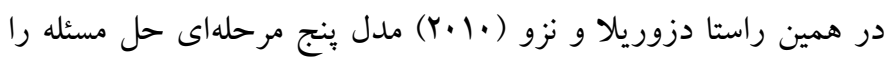
جنين توصيف نمودهاند: ا. روى آورد به مسئله: افراد ذهنيت حل مسئله مى يابند و قادر مى تصى

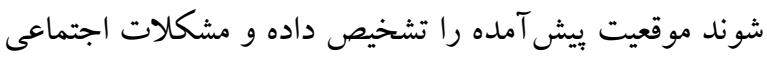
را به عنوان بخشى از زندگى روزمره در كك كنند.

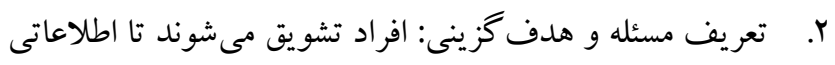

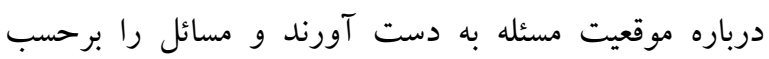

5. Problem Definition And Formulation

${ }^{6}$. Goal Setting

7. Generation Of Alternative Solutions

${ }^{8}$. Solution Implementation And Verification
مقام do

حل مسئله اجتماعى، يكك فر آيند شناختى - رفتارى است كه در آن فرد مى كوشد براى موقعيت هاى مشكل آفرينى كه در زندگى روزمره با با آنها

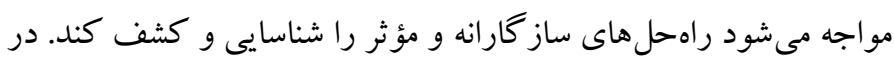

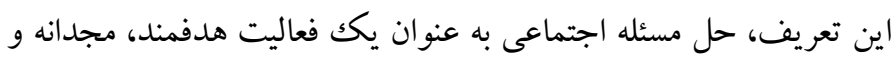

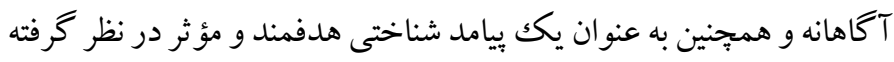

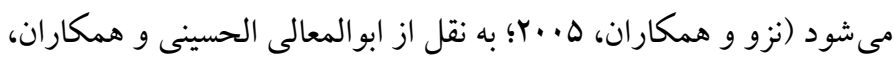
.(1TM

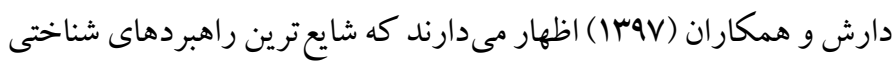
حل مسئله شامل؛ حدس زدن و آزمايش كردن، ساختن يك ليست منظم،

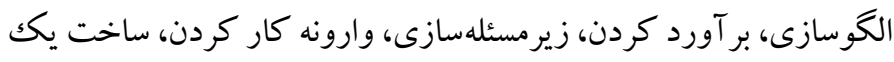
جدول و استدلال منطقى هستند (به نقل از فلاحان، محمودنيا، قائدى و ضرغامى، 9911). حل مسئله بين فردى در ينج مرحله مطرح شده است:

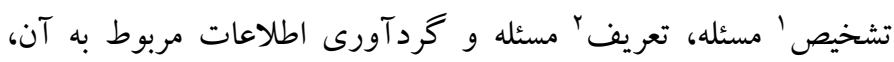

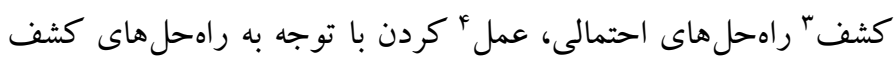
شده و مرور مراحل كذشته و ارزشيابى نتايج فعاليتهاى انجام شده رهاه

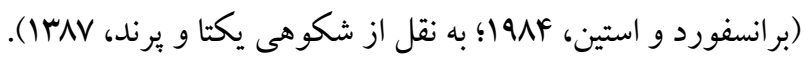
در الكوى ديخر مهارتهاى حل مسئله بين فردى شامل جهار مؤلفه مهارت

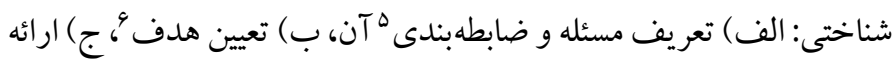

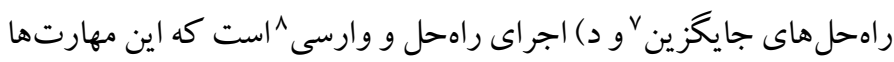

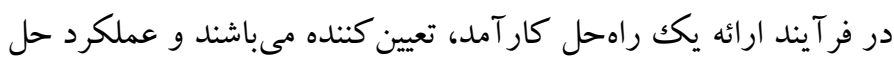

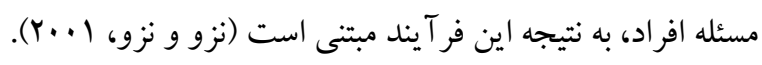

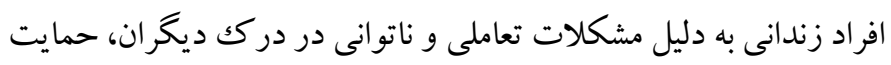

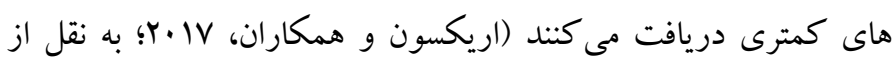

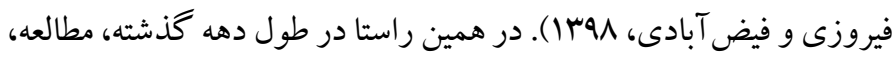
كاربست، آموزش و درمان برنامهاى شناختى - رفتارى از جمله حل حل مسئله بين فردى براى زندانيان كسترش قابل ملاحظهاى داشته است (خدايارى فرد برد

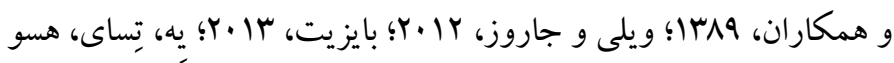

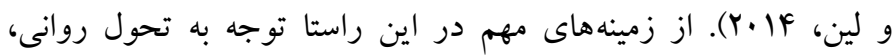

1. Identify

2. Define

${ }^{3}$. Explore

4. Act 
با گروه گُوه است. در اين طرح، با انتساب تصادفى ميان گروه آزمايش و كواه تقسيم شدند و سبس مداخله اجرا شدو.

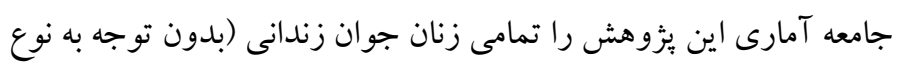

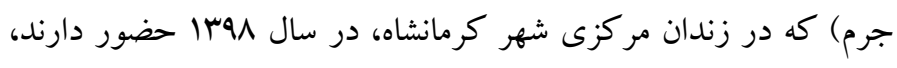
تشكيل مىدهد. طبق گزارش واحد تحقيقات اداره كل سازمان زندانها

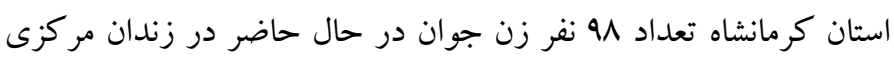
زنان در حال كذراندن دوران محكوميت خود هستند. تعداد ·ب نفر به عنوان نمونه انتخاب و به صورت انتساب تصادفى در دو گروه آزمايش (هان انفر )

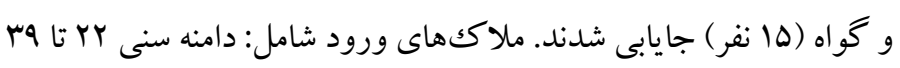

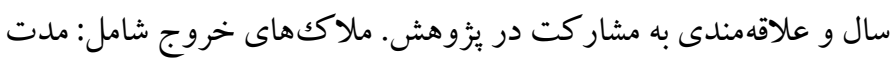
حبس كه كمتر از F ماه، عدم علاقه و همكارى در شر كت در جله جلسات

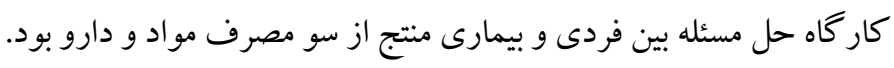
اين بزوهش در شوراى بثزوهشى دانشگاه آزاد اسلامى واحد كرمانشاه مورد

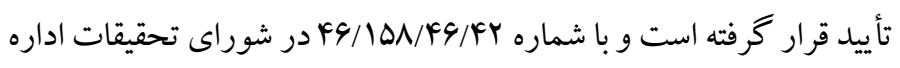

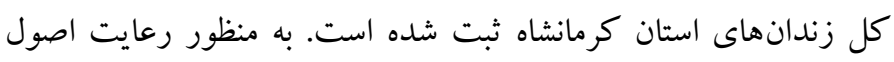

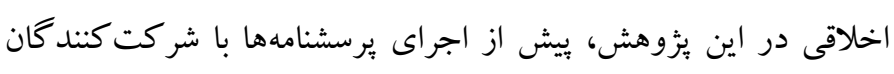

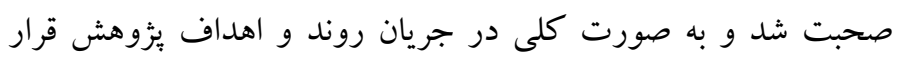
كرفتند. افراد آزادى كامل داشتند تا در صورت صورت عدم تمايل در بثروهش

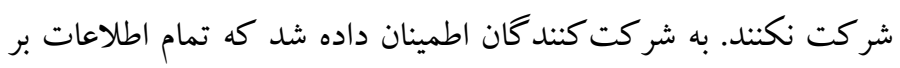
اساس اصل رازدارى، محرمانه مىباشد و براى امور يزٔوهشى مورد استفاده

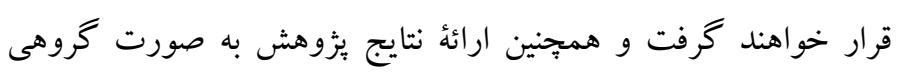
خو اهد بود. ب) ب ابز ار برسشنامه حل مسئله اجتماعى: در اين يزوهش، براى ارزيابى توانايى حل

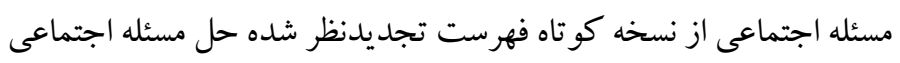
دزوريلا، نزو و مديو -اليوراس كه در سال F .... ساخته شده است. اين ابزار

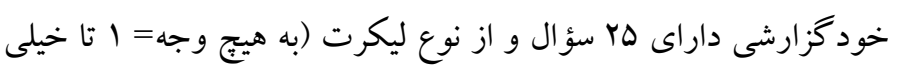

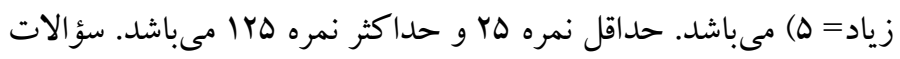

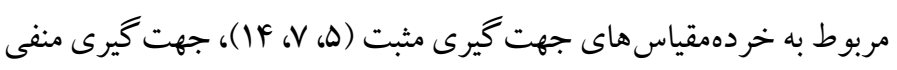

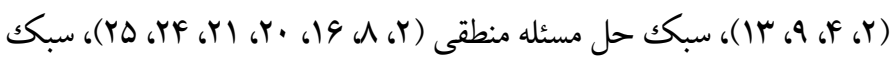

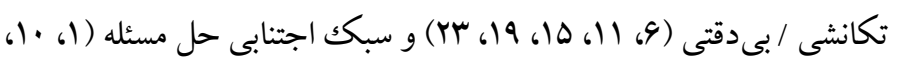

فراوانى، طول مدت، بيجيديدگ و بزرگى و كوجكى آن بررسى كنند. r. توليد راهحلهاى جايگزين: طى اين مرحله دامنهاى از راهحل هاى احتمالى ابداع مى شود و شر كت كنند گان تشويق مى شوند كه خلاق بوده و ياسخهاى خود را سانسور نكنئ.

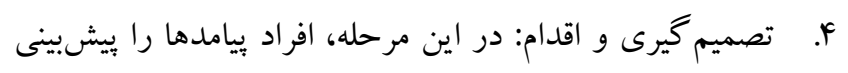

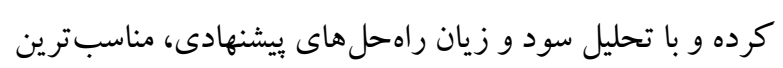
آنها را كزينش مى كنند.

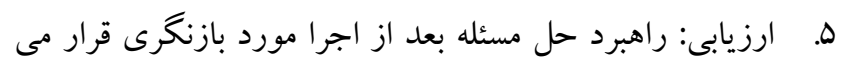
كيرد، اخر اهداف تحصيل شده باشد، حل مسئله موفقيت آميز بوده و در غير اينصورت فر آيند حل مسئله در يرتو اطلاعات نوينى تكرار مى شود.

شواهد تجربى گسترده روانشناسى جنايى نشان مىدهد كه فقدان مهان مهارت هاى شناختى و نقص در حوزههاى تصميم گيرى، كنترل خود، تفكر نقادانه

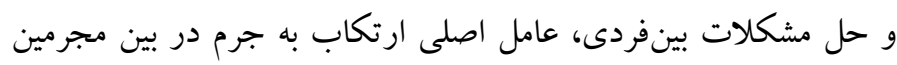

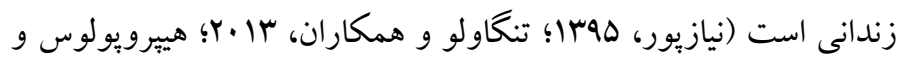

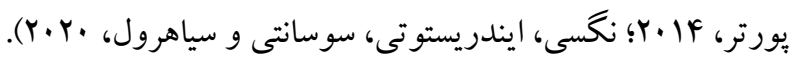

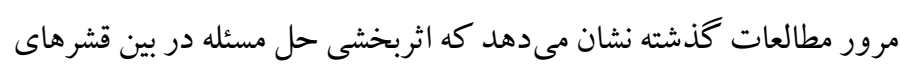
مختلف (جامعه ييشدبستانى، دانش آموزان، جوامع بالينى و...) بررسى شده

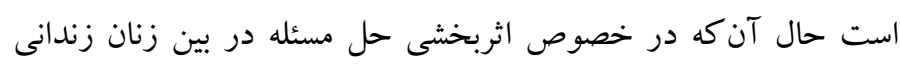

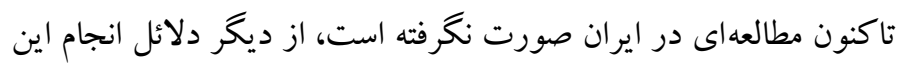

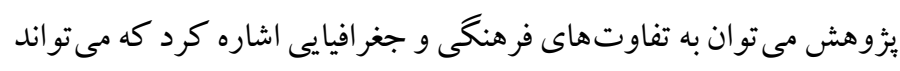
بر غناى دانش و اطلاعات بيرامون زنان زندانى بيافزايد، از سويى اقدام جهت افزايش حل مسئله در بين زنان زندانى مى تواند علاوه بر كاهش ونش مشكلات و در گيرىهاى بين فردى در زندان، به ساز گارى بيشتر با محيط ديط

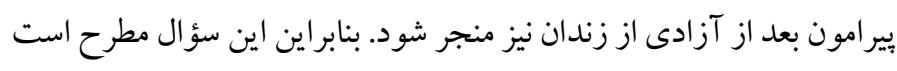
آيا آموزش حل مسئله بينفردى بر حل مسئله اجتماعى زنان جوان زند زئداني اثربخش است؟

روش الف) طرح يثوهش و شر كت كنند كان: يُوهش حاضر با توجه به هدف

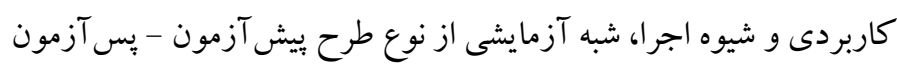


آزمايشى، ابزارهاى حل مسئله اجتماعى، توسط هر دو گروه آزمايشى و

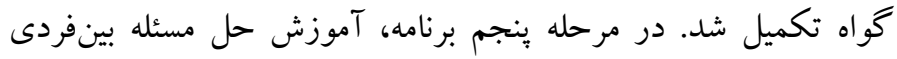

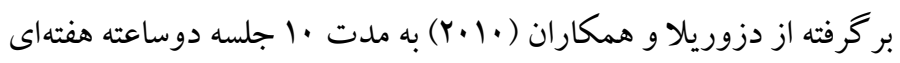

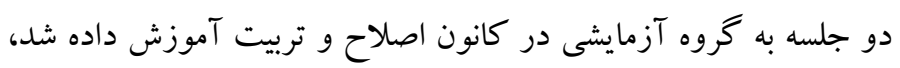

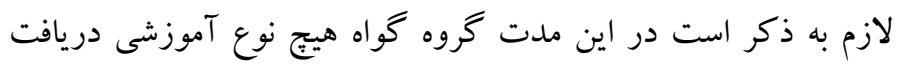

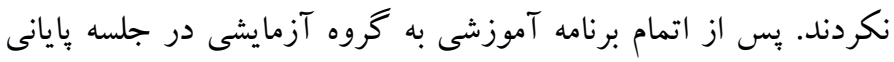

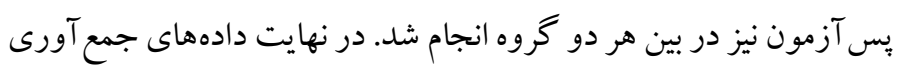

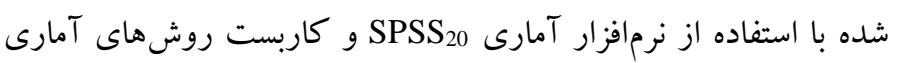

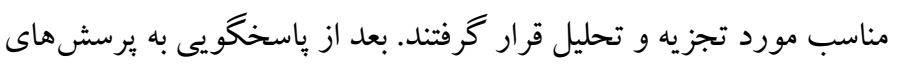

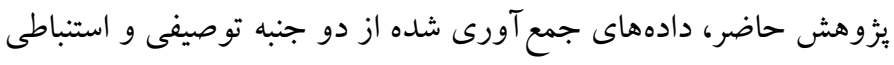

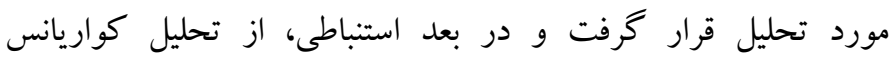
جندمتغيرى و يككراهه استفاده شد.

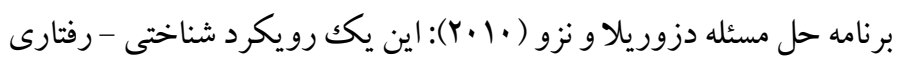

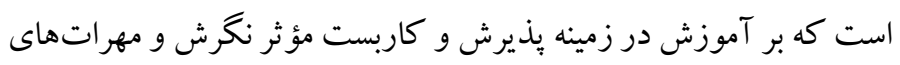
حل مسئله انطباقى متمر كز است. اين روش درمانى يكك رويكرد مثبت نسبت به مداخه بالينى است و هدف آن نه تنها كاستن از آسيب روانى بلكه

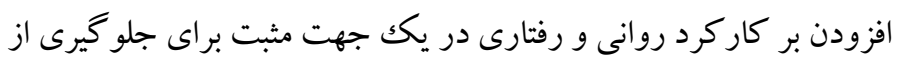

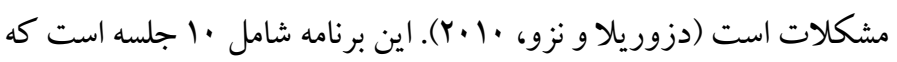
توضيحات آن در جدول اذكر شده است.

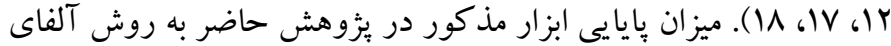

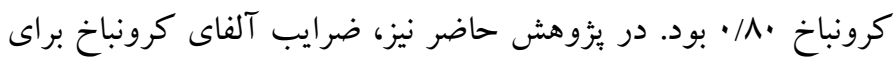
عامل هاى جهت گيرى مثبت، جهت گيرى منفى، سبك منطقى حل مسئله،

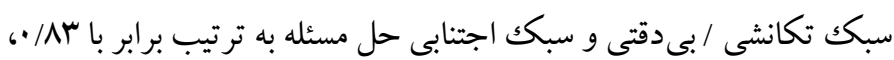

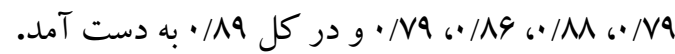
درستى و قابليت اعتماد نسخه كو تاه فهرست تجديدنظر شده حل مسئله

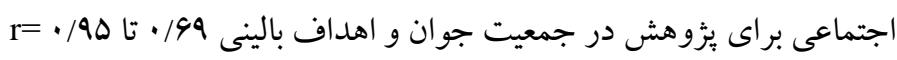
به دست آمده است. همجينين درستى سازه اين برسشنامه نيز با استفاده از

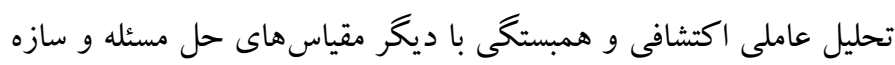

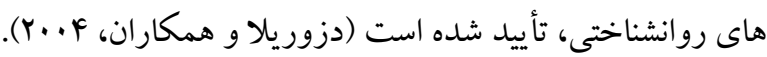

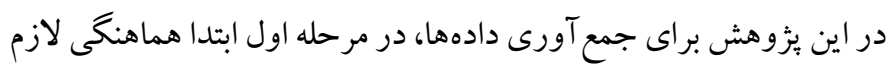

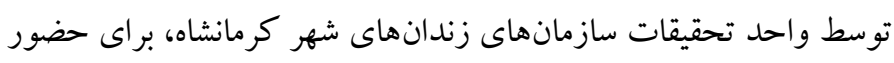

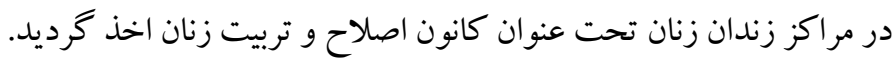
سبس در مرحله دوم، با حضور در زندان زنان و با همكارى كارشناسان

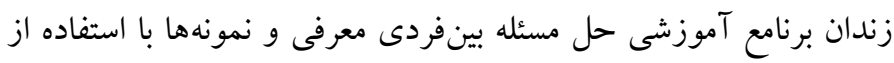

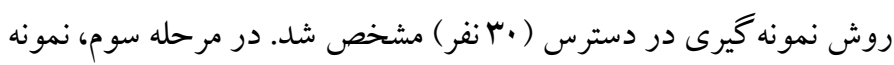

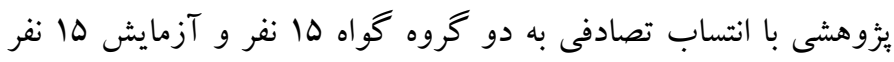

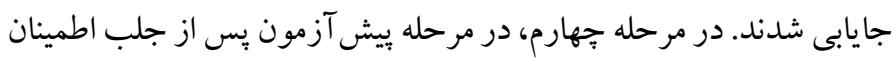

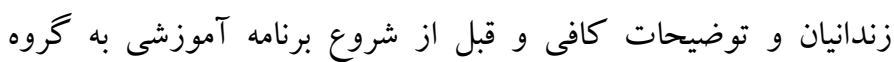

جدول ا. محتواى جلسات برنامه تلفيقى حل مسئله محور (دزوريلا و نزو، • + ب)

\begin{tabular}{|c|c|c|c|}
\hline 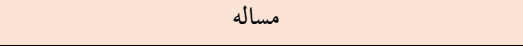 & محتوا & اهداف & عناوين جلسه \\
\hline از شر كت كنند كان خواسته شد كه ليستى از مشكلات خود & آشنايى با دوره؛ تشريح اهداف كار كاه و بررسى اهميت آن به قابه & 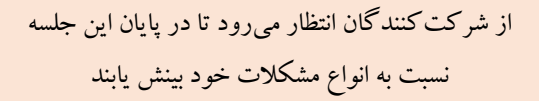 & جلسه اول \\
\hline از شر كت كندكان خواسته شد تا از بين مسائل خود & تشريح و تعريف مشكلات، معضلات و تبديل آنها به مسئله و & 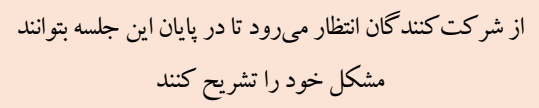 & 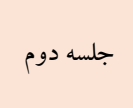 \\
\hline از شركت كندكان خواسته شد تا علل ايجاد مسئله خود را & تعريف، تشخيص و تجزيه مشكل يا مسئله & از شركت كند كان انتظار مىرود تا در بيايان اين جلسه مسئله & جلسه سوم \\
\hline از شر كت كند كان خواسته شد تا منافع حل مسئله خود را & تعيين اهداف دست يافتى براى حل مسئله & از شركت كند كان انتظار مىرود تا در بايان اين جلسه اهداف & جلسه جهارم \\
\hline از شركت كنند كان خواسته شد تا راههاى حل مسائل خود را & ايجاد راهحل ها و تشريح روش بارش ذهنى & 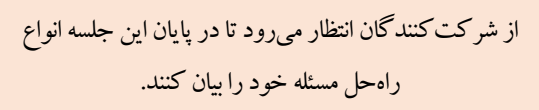 & جلسه ينجم \\
\hline 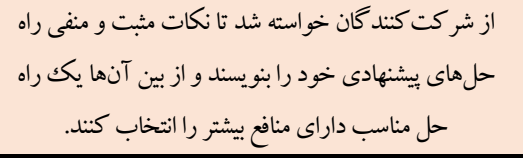 & ارزيابى و انتخاب راهحل و جَگونخى سنجش مثبت و منفى & 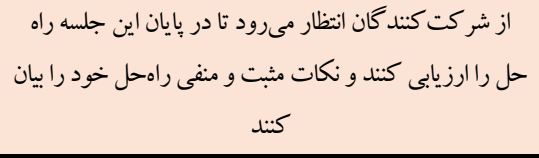 & جلسه ششم \\
\hline
\end{tabular}




\begin{tabular}{|c|c|c|c|}
\hline مساله & محتوا & اهداف & عناوين جلسه \\
\hline 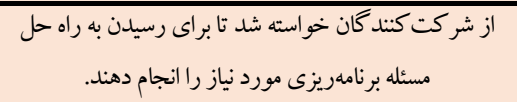 & اجراى راهحل هاى ترجيحى & از شركت كند رًان انتظار مىرود تا در بايان اين جلسه برنامه مناسب براى راهحل مسئل خود را بيان كند. & جلسه هفتم \\
\hline 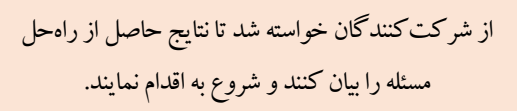 & ارزيابى نتايج و جخونخى نحوه ثبت آن در بركه تكاليف & از شركت كنند كان انتظار مىرود تا در يايان اين جلسه از راه & جلسه هشتم \\
\hline نظر مسئله را بنويسند و در صندان خواسته شد تا بهترين نتيجه راهحل مورد نداشتن رضايت، راهحل & 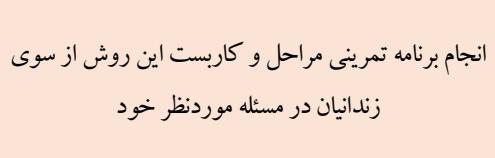 & از شركت كند كان انظظار مىرود تا در بايان اين جلسه راه & جلسه نهم \\
\hline در بايان از شركت كنند كان خواسته شد نتيجه گيرى كلى از & جمعبندى كار كاه، مرور نكات اصلى و يرس و ياسخ & از شركت كند آنان انتظار مىرود تا در بايان اين جلسه جمع & جلسه دهم \\
\hline
\end{tabular}

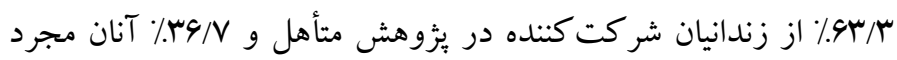

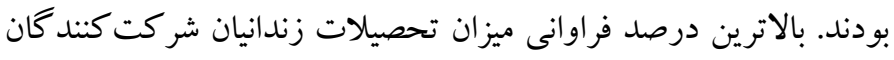

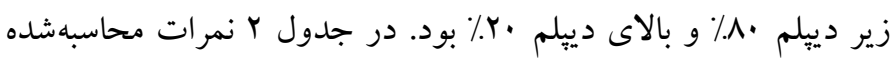
شاخصهاى توصيفى مؤلفهاى حل مسئله اجتماعى در بين زنان جوان

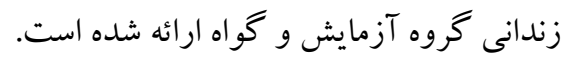

حداقل سن زندانيان 19 سال و حداكثر سن آنان ^ب سال است و ميانگين

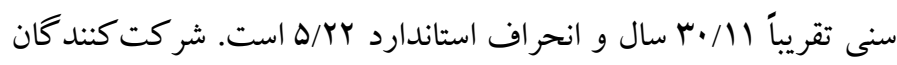

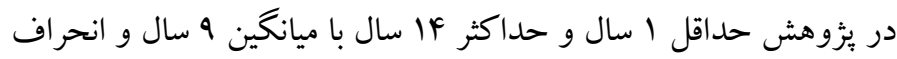

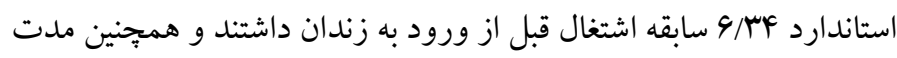

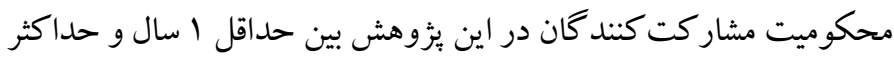
IV سال، با ميانخين تقريباً

\begin{tabular}{|c|c|c|c|c|c|}
\hline \multicolumn{2}{|c|}{ كو اه } & \multicolumn{2}{|c|}{ آزمايش } & \multirow{2}{*}{ مرحله } & \multirow{2}{*}{ متغير } \\
\hline انحر اف معيار & ميانگين & انحر اف معيار & ميانخين & & \\
\hline$r / 49$ & $F / 1 r$ & r/Ar & $r / \cdot V$ & يِش آزمون & \multirow{2}{*}{ جهت گيرى مثبت } \\
\hline T/M & $F / Y Y$ & $r / F i$ & $V / 90$ & پِ آزمون & \\
\hline $1 / 99$ & $9 / 49$ & $r / \cdot V$ & $9 / 94$ & ييش آزمون & \multirow{2}{*}{ جهت گيرى منفى } \\
\hline I/AF & G/Ar & $1 / 94$ & $k / q \Lambda$ & يس آزمون & \\
\hline$r / 91$ & $r / r q$ & $r / r V$ & $F / 19$ & يِيش آزمون & \multirow{2}{*}{ سبك منطقى } \\
\hline$r / F F$ & $F / F V$ & $r / \cdot r$ & $9 / Y 1$ & ״ֶ آزمون & \\
\hline r/A & $\Delta / \wedge \varphi$ & $r / 19$ & $\Delta / 9 \Lambda$ & يُش آزمون & \multirow{2}{*}{ تكانش گرى / بىدقتى } \\
\hline$r / 91$ & $9 / 1 V$ & $r / 9$. & $r / 11$ & بָ آزمون & \\
\hline$r / V q$ & $\Delta / 1$. & $\mathrm{r} / \Lambda$ & $0 / 99$ & ي يِش آزمون & \multirow{2}{*}{ سبكك اجتنابى } \\
\hline $1 / W V$ & $F / \Delta q$ & $1 / 9 V$ & $r / v 1$ & يس آزمون & \\
\hline
\end{tabular}

آزمايشى و كنترل در بس آزمون براى متغيرها تأييد شدند، به عبارت ديخر

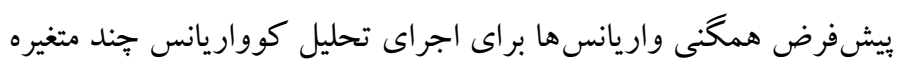

$$
\text { برقرار است. }
$$

نتايج جدول ب شامل نتايج آزمون تحليل كوواريانس جند متغيرى، تفاوت

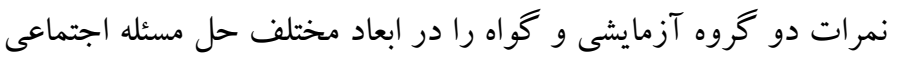

قبل از تحليل كواريانس مفروضههاى آن بررسى شد. سطوح معنىدارى

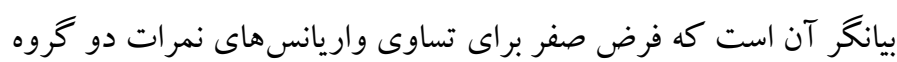

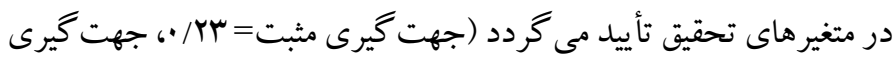

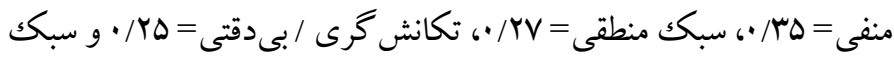

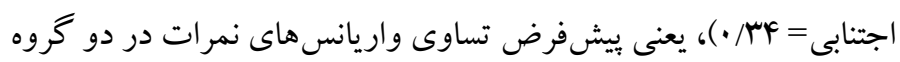


گروههاى آزمودنى تبيين مىشود (T94/.

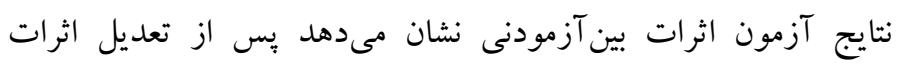

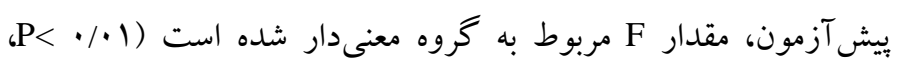
F= Ir/IrV اختلاف معنىدارى بين نمرات كل آزمودنىها در بـ بس آزمون وجود داشته است و به/ • واريانس متغير سبك منطقى توسط گروههاى آزمودنى تبيين

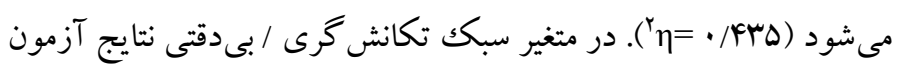

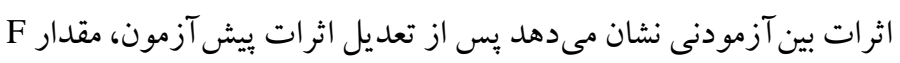

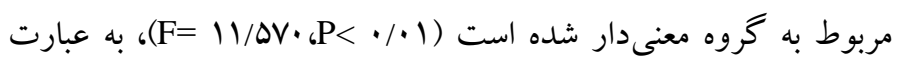
ديخر بِ از خارج كردن اثرات بيش آزمون، اختلاف معنىدارى بين

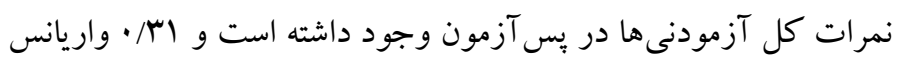

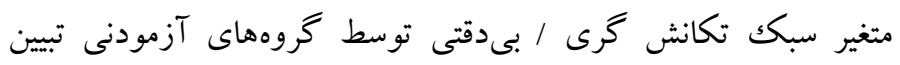

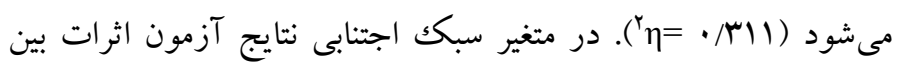

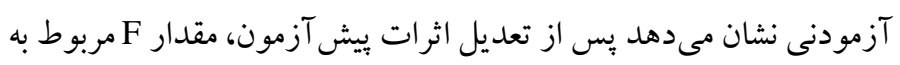

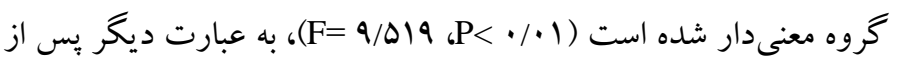
خارج كردن اثرات يِيش آزمون، اختلاف معنىدارى بين نمرات كل

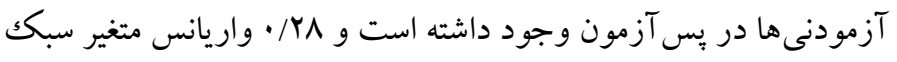

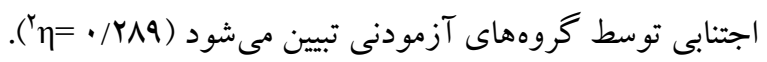

نشان مىدهد. با در نظر كرفتن مجذور إتا مىتوان كفت كه 94٪ اين

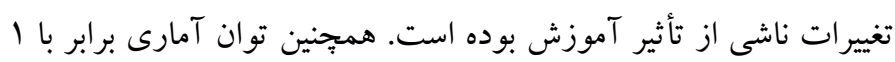

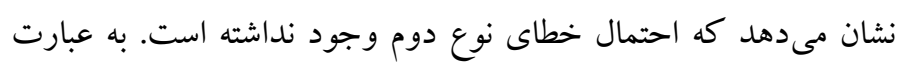

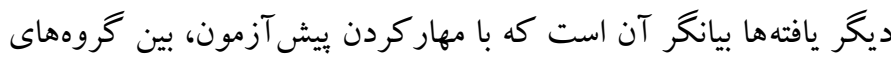
آزمايشى و كواه حداقل از لحاظ يكى از متغيرهاى وابسته (خرده

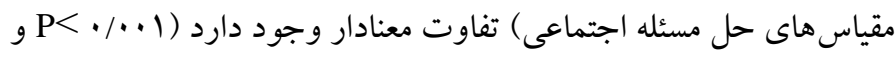
هـ/F=11). براى بـ بردن به تفاوتها، نتايج حاصل از تحليل كواريانس، در جدول F نشان داده شده است.

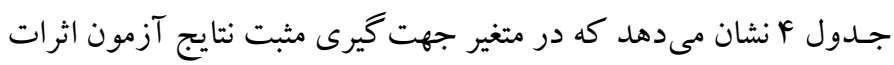

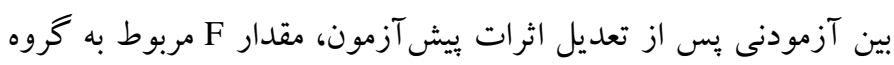

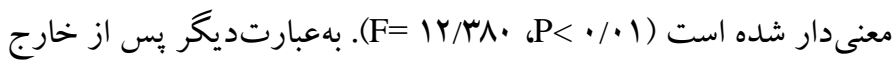

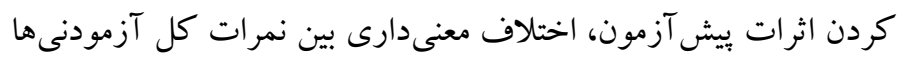

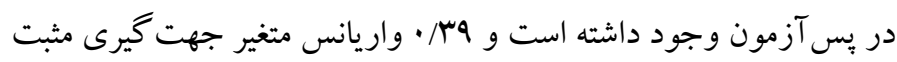

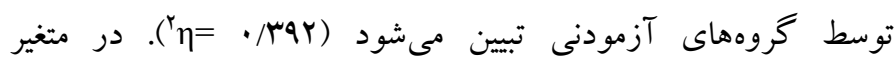

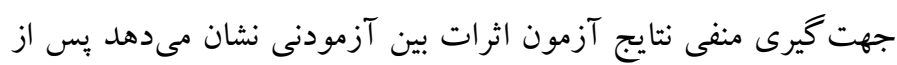

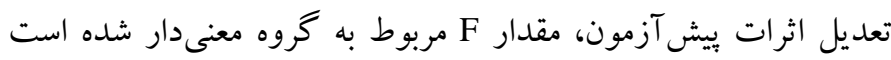

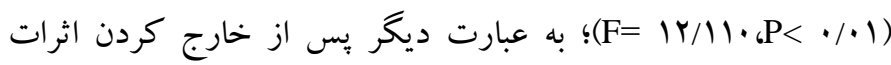
بيش آزمون، اختلاف معنىدارى بين نمرات كل آزمودنىها در بس بـ آزمون

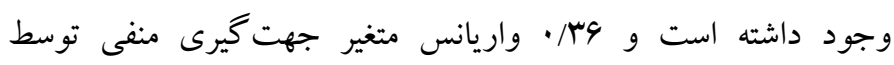

\begin{tabular}{|c|c|c|c|c|c|c|c|c|}
\hline توان آمارى & مجذور اتا & $\mathrm{P}$ & $\mathrm{F}$ & df2 & df1 & مقدار & آزمون & شاخص آمارى \\
\hline 1 & . & $\cdot 1 \cdot \cdot 1$ & $11 / r \Delta$ & $r \wedge$ & 1 & $\cdot / r \cdot V$ & لامبداى ويلكز & كروه \\
\hline
\end{tabular}

\begin{tabular}{|c|c|c|c|c|c|c|c|}
\hline توان آمارى & مجذور اتا & $\mathrm{F}$ & ميانگگين مجذورات & df & مجموع مجذورات & منبع تغييرات & متغيرها \\
\hline 1 & - Mar & IY/TA. & VY/YYq & 1 & VY/YYG & كروه & جهت گيرى مثبت \\
\hline 1 & - /499 & $|Y / 1|$ & $V Y / Y I$. & 1 & $V Y / Y I$. & كروه & كيرى منفى \\
\hline 1 & . Arts & IT/IrV & VN/GYS & 1 & VN/GYS & كروه & كـ منطقى \\
\hline 1 & $\cdot / 411$ & $11 / \Delta V$. & $91 / 999$ & 1 & $91 / 999$ & كروه & كانش كرى /بىدقتى \\
\hline 1 & 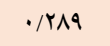 & $9 / 019$ & $91 / r g 4$ & 1 & $91 /$ raf & كروه & سبك اجتنابى \\
\hline
\end{tabular}

نشان داد كه آموزش برنامه حل مسئله بين فردى باعث افزايش و بهبود در

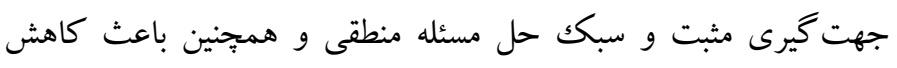
كاربست جهت گيرى منفى، سبككهاى حل مسئله اجتنابى و تكانشى / بى ونى
بحث و نتيجه كيرى يزوهش حاضر براى بررسى آموزش حل مسئله بينفردى بر حل مسئله در

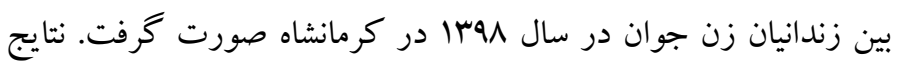


در راستاى تبيين نتايج يزوهش حاضر بايد تأكيد كرد برنامه حل مسئله بين

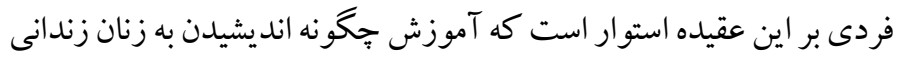

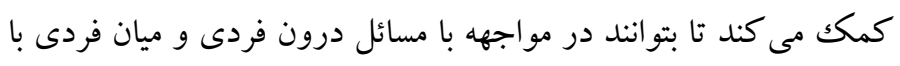

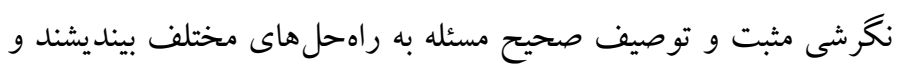

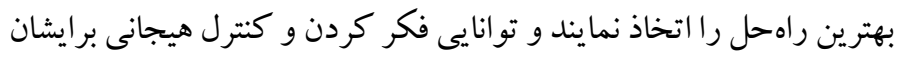
ميسر گردد. در مجموع بايد كفت كه مهارتهاى حل مسئله بين فردى، به عنوان توانايى خلق راهكارهاى مختلف براى حل مسائل و توجه به بيامدهاى

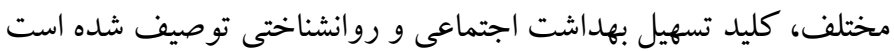
و افرادى كه فاقد مهارتهاى شناختى مسائل بينفردى هستند، بيشتر

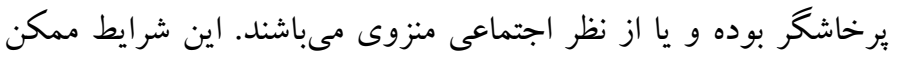

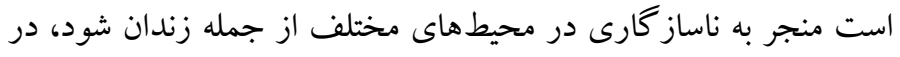

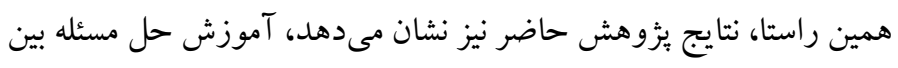

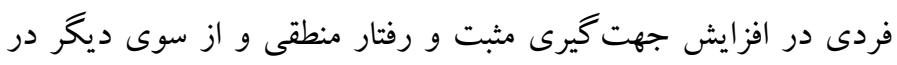

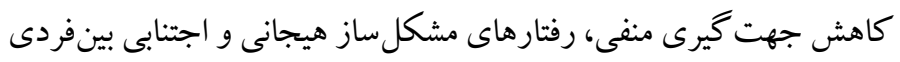
زنان زندانى در فضاى زندان مؤثر بوده است.

يُزوهش حاضر با محدوديتهايى روبرو بود از جمله اين كه استفاده از

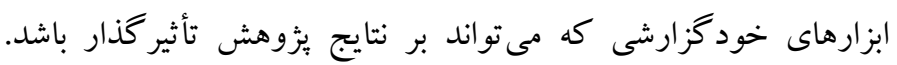

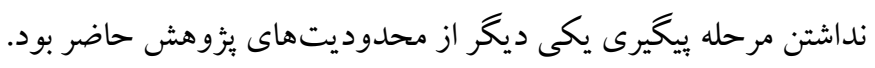
با توجه به نتايج يزوهش حاضر در راستاى اثربخشى آموزش حل مسئله بين فردى در نمونه زنان جوان زندانى در غالب متغيرهاى وابسته موردمطالعها،

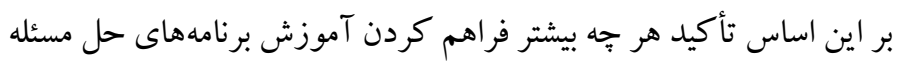

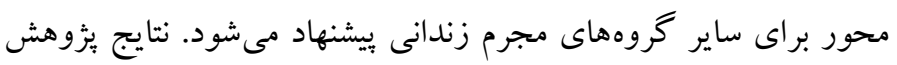
حاضر اطلاعات كاربردى مفيدى در رابطه با ارتقاء حل مسئله زندانيان در اختيار مسئولين اين سازمان قرار داده است، بنابراين ييشنهاد مىشود در برنامهريزىهاى اصلاحى، تربيتى و آموزشى براى زندانيان برنامهاى حل

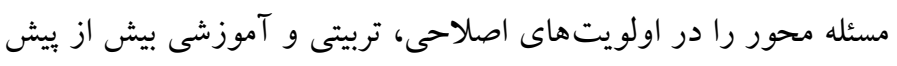

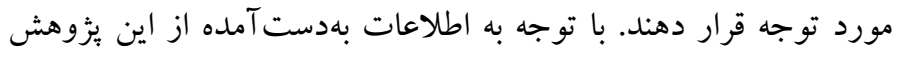

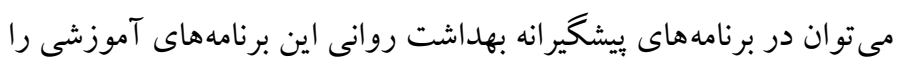

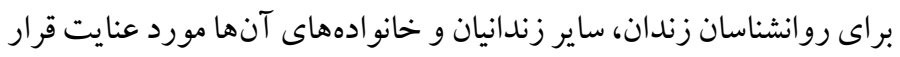

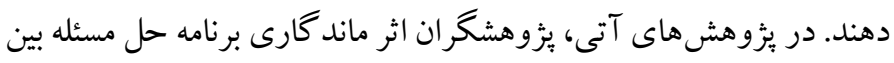

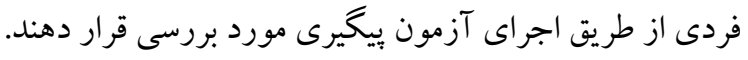

دقتى شده است. به عبارت ديخر، در مقايسه با گروه گو اه، ميانگين نمر ات

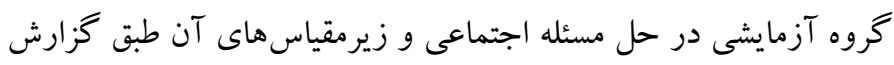

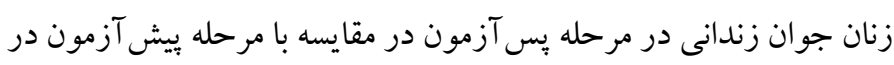

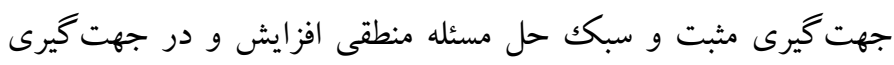
منفى، سبكك هاى حل مسئله تكانشى و اجتنابى كاهشي ميافته است.

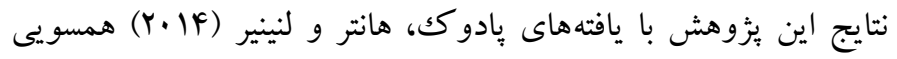

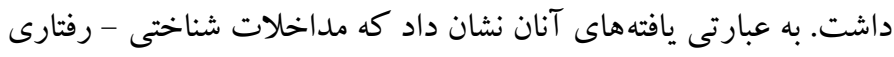

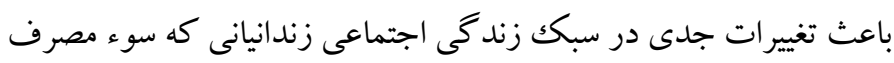

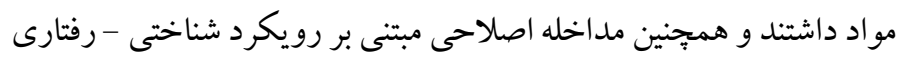

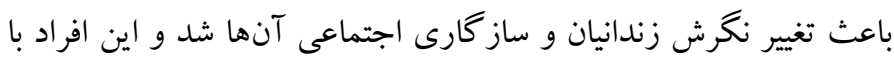

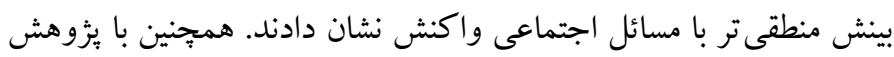

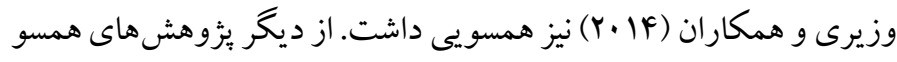
با يافتهاى اين مطالعه مىتوان به مطالعات يتوسن-داويس و همكاران

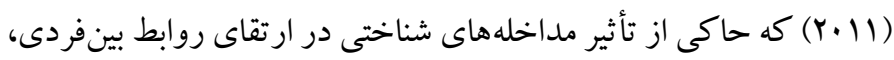
افزايش اعتماد به نفس و مؤلفههاى حل مسئله اجتماعى در ميان زندانيان

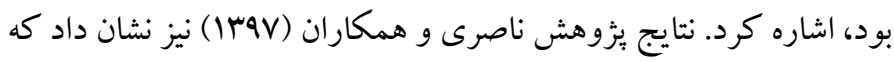
كنترل و نظارت مناسب در زندان باعث افز ايش مشار كت اجتماعى زندانيان

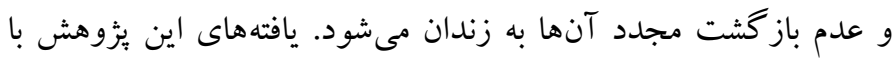

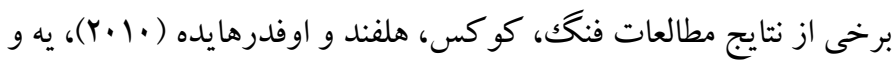

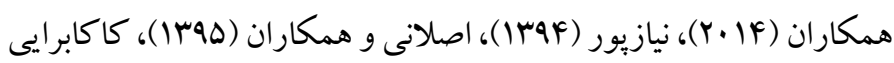

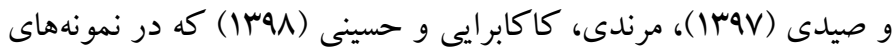
مختلفى انجام شده بود همخوانى داشت.

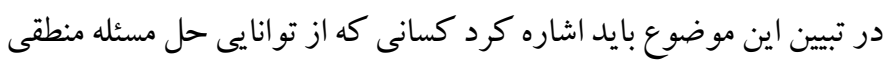

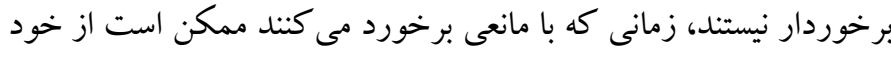

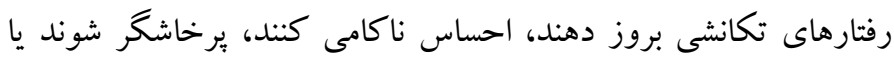
كوشه گيرى را بهعنوان راهبرد مقابله با موقعيت مشكل ساز اتخاذ نمايند

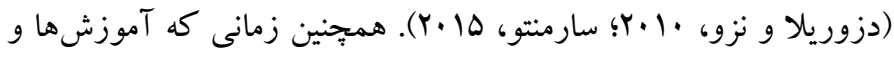
دستو رالعمل هاى صريح و آشكارى درباره فرايند تعريف و بيان مسئله ارائه

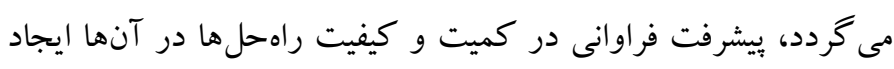

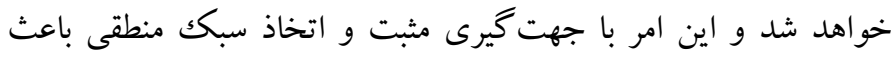
كاهش رفتارهاى منفى مىشود و رفتارهايى نظير همكارى و همدردى با مناي

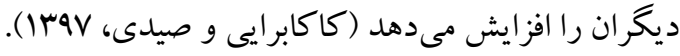


نقش هر يك از نويسند كان: نويسنده اول محقق اصلى اين يُوهش است. نويسنده دوم، استاد راهنما مىباشند. تضاد منافع: نويسند گان در رابطه با اين مقاله تضاد منافعى ندارند. قُشكر و قدردانى: بدين و سيله از كسانى كه در اين بثزوهش شر كت دا شتند تشكر و

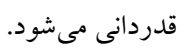

ملاحضات اخلاقى وييروى از اصول اخلاق ئولوهش: اين مقاله برگرفته از رساله دكترى نويسنده نخست

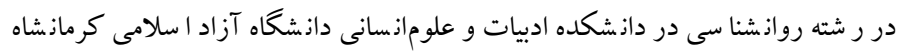
است. جهت انجام يزٔوهش مجوزهاى مربوطه از سازمان زندانهاى ا ستان كرماذشاه اخذ شد. حامى مالى: اين يُزوهش حامى مالى نداشته است. 


\section{References}

Abolmali Alhosseine, Kh., Golnar, M., Monadi, M., Khosravi, Z., Nazerzade Kerman, F. (2009).The Effects of Cognitive-Behavioral instructive Method on improving Social Cognition among male delinquents. Journal of Psychologoical studies, 5 (2); 45-72. [link]

Alevizopoulos, G., \& Igoumenou, A. (2016). Psychiatric disorders and criminal history in male prisoners in Greece. international journal of law and psychiatry, 47, 171-175. [link]

Aslani, J., ahmmaddost, H., Bahmani, M. (2016).The Effectiveness of Positive Psychotherapy on Depression Symptoms and Subjective Well - Being of Prisoners. Positive psychology research, 1 (4): 67-76. [link]

Bakker, L.W., \& Hudson, S.M., \& Ward, T. (2000). Reducing recidivism in driving while disqualified: A treatment evaluation. Criminal Justice and Behavior, 27 (5), 531-560.[Link]

Bayazit, I. (2013). An Investigation of Problem Solving Approaches, Strategies, and Models Used by the 7th and 8th Grade Students when Solving Real-World Problems. Educational sciences: theory \& practice, 13(3).1920-1927. [link]

Bowler, N., Phillips, C., \& Rees, P. (2018).The association between imported factors and prisoners' mental health: Implications for adaptation and intervention.International journal of law and psychiatry, 57: p. 61-66. [link]

D'Zurilla, T. J., \& Nezu, A. M. (1990). Development and preliminary evaluation of the Social ProblemSolving Inventory. Psychological Assessment. A Journal of Consulting and Clinical Psychology, 2 (2), 156-163.[link]

D'Zurilla, T. J., Nezu, A. M., \&Maydeu-Olivares, A. (2004). Social problem solving: theory and assessment. in e. c. chang, t. J. D'zurilla, \& 1. J. Sanna (eds.), Social problem solving: theory, research. 11-27. [link]

D'Zurilla, T. J., \& Nezu, A. M. (2010). Problem-solving therapy. In K. S. Dobson (Ed.), Handbook of cognitive-behavioral therapies (pp. 197-225). Guilford Press[link]

Fagan, T. J., Cox, J., Helfand, S.,\& Aufderheide, D. (2010). Self-injurious behavior in correctional settings. Journal of Correctional Health Care, 16(1), 48-66.[link]

Falahan, Z., Mahmodnia, A., Ghaedy, Y., \& Zarghami, S. (2020). Explanation of influence of the cognitive elements of philosophical research methods to improving the math problem solve training. Journal of Psychological Sciences. 19 (90); 677-686. [link]

Farid Marandi, B., Kakabaraee, K., \& Hosseini, S.A. (2020). The Effect of Problem- Solving Training on Social Skills of Preschool Children. Journal of Child Mental Health. 6 (4):131-143. [link]

Firoozi, M., \& Feizabadi, Z. (2019). Behind the wall of violence: psychological impairment of premeditated and impulsive aggression in compare to non - aggressive individuals in prison. Journal of Psychological Sciences 18 (81); 1029-1036. [link]

Harris, PH., Mennis, J., Obradovic, Z., Izenman, A., Grunwald, H., \& Lockwood, B., et al. (2012). Investigating the Simultaneous Effects of Individual, Program and Neighborhood Attributes on Juvenile Recidivism Using GIS and Spatial Data Mining. NCJ 237986, Rockville, MD, USA: National Institute of Justice/NCJRS. [link]

Hiropoulos A., \& Porter J. (2014). Visualizing Property Crime in Gauteng: Applying GIS to crime pattern theory. South African Crime Quarterly, 47: 1728. [link]

Jones, M., Burge, S., Sharp, S., \& McLeod, D. (2020). Childhood adversity, mental health, and the pepertation of physical violence in the adult intimate relationships of women prisoners: A life course approach. Child Abuse \& Neglect, 101, 104123.[link]

Kakabaraee, K., \& Seidy, M. (2018). The Effectiveness of Interpersonal Problem Solving Skills Training on Social Problems of Preschool Students. Journal of Applied Psychological Research. 9 (4); 159175.[link]

Khodayarifard, M., Yonesi, J., Akbari Zardkhaneh, S., Fagihi, A.N., \& Behpajouh, A. (2010). Group and Individual Cognitive Behavioral Therapy Based on Prisoners' Religious Knowledge. Research in Psychological Health. 3 (4):55-68. [link]

Nengsyi, E., Indriastuti, D., Prasetya, A., Susanti, R., \& Syahrul, S. (2020). The needs of being loved and loving among women prisoners in a women's 
penitentiary in Indonesia: A qualitative study. Enfermería Clínica, 30, 272-275.[link]

Nezu, A.M., \& Nezu, C.M. (2001). Problem Solving Therapy. Journal of Psychotherapy Integration 11, 187-205. [link]

Niazpour, A.H. (2017). Criminological Analysis Of Prisoners Classification. The Judiciary law Journal, 80 (96); 173-201. [link]

Paddock, S. M., Hunter, S. B., \& Leininger, T. J. (2014). Does group cognitive-behavioral therapy module type moderate depression symptom changes in substance abuse treatment clients? Journal of substance abuse treatment, 47(1), 78-85.[link]

Pettus-Davis' C.,Howard, M., Lewis, 1., \& Scheyett, A. (2011). Naturally occurring Social Support in Interventions for Former Prisoners with Substance Use Disorders: Conceptual Framework and Program Model. Journal of Criminal Justice, 39(6), 479-488. [link]

Sarmento, M. (2015). A mental health profile of higher education students. journal of social and behavioral sciences.191 (6): 12-20.[link]

Shokohi Yekta, M., \& Parand, A. (2008). The Effectiveness of Instruction Based on Cognitive Approach on Family Relationship. Family Research, 4 (1); 5-16. [link]

Thangavelu A., Sathyaraj S.R., \& Balasubramanian S. (2013). Assessment of Spatial Distribution ofRural Crime Mapping in India: A GIS Perspective, International Journal of Advanced Remote Sensing and GIS, 2(1): 70-85. [link]

Vaziri, SH., LotfiKashani, F., Jamshidifar, Z., Vaziri, Y., \& Jafari, M. (2014). Group Counseling Efficiency based on Choice Theory on Prisoners' Responsibility Increase.Procedia - Social and Behavioral Sciences, 128, 311-315.[link]

Wiley, J., \& Jarosz, A. F. (2012). Working memory capacity, attentional focus, and problem solving. Current Directions in Psychological Science, 21(4), 258-262.[link]

Yeh, Y.C., Tsai, J.L., Hsu, W.C., \& Lin, C. F. (2014). A model of how working memory capacity influences insight problem solving in situations with multiple visual representations: An eye tracking analysis. Thinking Skills and Creativity, 13,153-167.[link] 